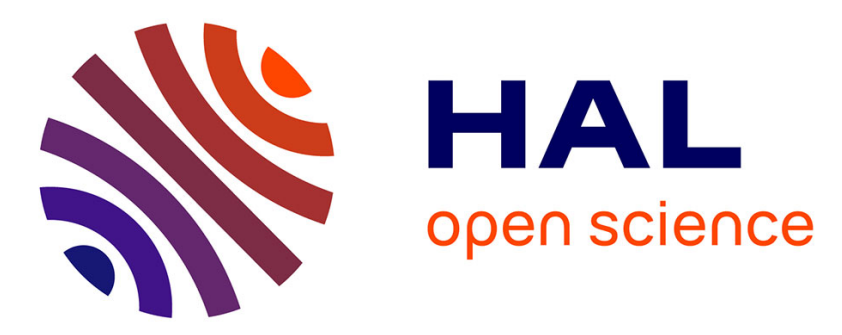

\title{
Prevalence and correlates of seclusion and restraint use in children and adolescents: a systematic review
}

\author{
Marc Hert, Nele Dirix, Hella Demunter, Christoph U. Correll
}

\section{To cite this version:}

Marc Hert, Nele Dirix, Hella Demunter, Christoph U. Correll. Prevalence and correlates of seclusion and restraint use in children and adolescents: a systematic review. European Child and Adolescent Psychiatry, 2011, 20 (5), pp.221-230. 10.1007/s00787-011-0160-x . hal-00666479

\section{HAL Id: hal-00666479 https://hal.science/hal-00666479}

Submitted on 5 Feb 2012

HAL is a multi-disciplinary open access archive for the deposit and dissemination of scientific research documents, whether they are published or not. The documents may come from teaching and research institutions in France or abroad, or from public or private research centers.
L'archive ouverte pluridisciplinaire HAL, est destinée au dépôt et à la diffusion de documents scientifiques de niveau recherche, publiés ou non, émanant des établissements d'enseignement et de recherche français ou étrangers, des laboratoires publics ou privés. 
Prevalence and correlates of seclusion and restraint use in children and adolescents: A systematic review

Marc De Hert, Nele Dirix, Hella Demunter, Christoph U Correll

Word count: 3,362 (excluding references and tables)

Marc De Hert, University Psychiatric Centre KUL campus Kortenberg, Leuvensesteenweg 517, 3070 Kortenberg, Belgium, marc.de.hert@uc-kortenberg.be, +32(0)27580592.

Nele Dirix, School of Nursing Sciences KUL, Leuven Belgium.

Hella Demunter, University Psychiatric Centre KUL campus Kortenberg, Leuvensesteenweg 517, 3070 Kortenberg, Belgium.

Christoph U Correll, The Zucker Hillside Hospital, Glen Oaks, New York, USA. 


\section{Abstract}

Seclusion and restraint are frequent procedures to intervene in aggressive and potentially dangerous patients in psychiatric settings. However, little is known about their utilization and effectiveness in paediatric populations. We aimed to examine the prevalence and determinants of seclusion and restraint utilisation in children and adolescents in psychiatric settings. Using PubMed, PsychInfo and Cinahl, we performed a systematic literature review of studies published in the last 10 years reporting on the prevalence of seclusion and restraint use in psychiatrically ill youth ( $<21$ years old) treated in psychiatric settings. Only seven publications addressed the topic. Primary outcomes were prevalence rates, reported either as the proportion of patients restrained/secluded or as the number of restraints/seclusions per number of patient days. All studies found relatively high baseline rates of seclusion ( $26 \%$ of patients; $67 / 1.000$ patient days), and restraints (29\% of patients; $42.7 / 1,000$ patient days). In four studies an intervention, implemented to reduce seclusion and restraints, resulted in a dramatic weighted mean reduction in the more restrictive use of restraints by $93.2 \%$, with a $54.2 \%$ shorter duration. There was a small, weighted mean reduction in the use of less restrictive seclusions $(-0.6 \%)$, but results were heterogeneous $(-97.2 \%$ to $+71.0 \%)$, with the only increase in seclusions being reported in one study in which the intervention-based padded seclusion room was utilized more frequently instead of more restrictive measures. Otherwise, seclusion episodes reduced by $74.7 \%$, including a $32.4 \%$. shorter duration. Few studies reported on risk-factors and predictors, consisting of past or current aggression and/or violence, suicidal behaviour, more severe psychopathology, non-White ethnicity, emergency admissions, out-of-home placement, and poorer family functioning, while findings regarding age were inconsistent Except for duration, data about the effectiveness of seclusion and restraints were missing, although there is some indication that seclusion and restraints can lead to severe psychological and physical consequences. Future research should focus on indications, predictors, preventive and alternative strategies, as well as on clinical outcomes of seclusion and restraints in psychiatrically ill youth. In addition, there is a clear need for transparent policies and guidelines.

Keywords: Adolescents, agitation, aggression, children, intervention, restraints, review, seclusion, 


\section{Introduction}

Seclusion and restraint use (SRU) is a frequent intervention in psychiatric settings $[1,2,29,30,34]$. The literature prior to the year 2000 reports rates ranging from $28 \%$ to $60 \%$ $[1,4,10,15,23]$. A survey of 25 US child and adolescent units found 6 -fold higher SRU rates compared to adult services in the same state [18].

However, SRU has been questioned and criticized, as these procedures are considered to be invasive and coercive, and have the potential to escalate physical altercation and/or reduce treatment alliance. Dangerous behaviours, towards oneself or others, and agitation or aggression are the most frequently cited reasons for $\operatorname{SRU}[1,3,4,11,23,27,30]$. Safety concerns are given as the main reason for SRU by both patients and staff members [28]. According to surveys, three behavioural aspects often precede SRU in youngsters: threats [73\%], agitation [63\%] and physical aggression [63\%] [8].

Seclusion is generally defined as the placement of a patient in a specifically designed room in order to deescalate behaviours, assure physical safety and achieve behavioural control. Restraint use refers to a physical intervention, either through therapeutic holding by a caregiver/staff member or through the use of mechanical restraining tools [25].

In the literature on SRU, two lines of thought prevail. The first supports their use under specific circumstances. Dean et al. considers the interventions a humane and adequate intervention under three conditions [6]: 1) SRU should be part of a global therapeutic approach aimed at behaviour change, with a focus on prevention and use of the least restrictive measures; 2) the time of SRU should be as short as possible, and the patient should have frequent contacts and undergo close monitoring; and 3) SRU should only occur when disruptive and/or dangerous behaviours do not respond to less restrictive interventions, and SRU cannot be executed as punishment or out of indolence. Additionally, SRU has to be transparent, documented and available for internal- and external review in order to avoid abuse $[6,7]$. In many countries, SRU in minors requires parental consent in most non-urgent situations. A study by Petti et al. showed that $70 \%$ of paediatric patients felt respected in their dignity and privacy during SRU periods [28].

Other authors strongly oppose SRU and question their therapeutic value and effectiveness $[4,14,22,27]$. Many patients perceive SRU as coercive and aversive, which eliminates any potential therapeutic effect [4,24]. In addition, SRU can have severe 
consequences. SRU are not only traumatic for the individual (including a reactivation of prior trauma experiences), but they can also lead to serious physical side-effects such as asphyxia, aspiration, blunt trauma to the chest, thrombosis and mortality $[5,22,27,29]$. A study of Nunno et al. found 45 fatalities between 1993 and 2003 in child and adolescent psychiatric facilities related to restraints [26].

Ethical considerations regarding SRU are relevant. Not using SRU in severely ill or suicidal youngsters could be considered as refusing help to a person in needs or as neglect. On the other hand, overuse or systematic use to control 'difficult' behaviour, without clear guidelines, can be malpractice.

In order to evaluate the controversial use of SRU in children and adolescents, we performed a systematic literature review of studies that report on the frequency of SRU, aiming to assess its prevalence, as well as indications, determinants and outcomes. 


\section{Method}

A systematic review of the literature was performed using PubMed, Psychlnfo and Cinahl using the following search terms: "adolescent"; "adolescent psychiatry"; "aggression"; "child"; "child psychiatry"; "paediatric"; "restraint[s]" and "seclusion(s)". The reference lists of identified papers were used to find additional publications. We restricted our search to English language papers published between 2000 and 2010 because review papers on earlier research up until 1999 were already available [1,4,10,15,23]. Both the title and abstract of retrieved papers were screened.

The final selection of papers for review was based on the following inclusion criteria: Original research papers; target population aged between 6 and 21 years; psychiatric settings for children and adolescents; prevalence data on SRU presented in the results. If a paper did not meet all inclusion criteria, it was excluded.

Furthermore, the quality of the selected publications was assessed with the criteria proposed by Forbes and Griffiths [12]: clear aim and research questions; description of the sampling procedure; description of in- and exclusion criteria; clear description of the intervention [i.e., SRU]; description of the assessment methods/instruments; quality of data analysis; and results in accordance with aims or research question.

Data were analyzed using descriptive statistics and, when data were available, weighted means for seclusion or restraint use rates or frequencies were calculated. 


\section{Results}

Search results

The PubMed search yielded 79 hits. Based on the title and abstract, 9 papers could be included.

PsychInfo identified 580 potential papers, but only 8 additional publications were retrieved. Cinahl provided 41 hits whitout yielding any additional new papers. The reference search of the 17 papers identified 3 additional potential publications.

After applying the inclusion criteria, 13 publications were excluded: 6 did not meet the time-frame $[2,10,20,23,31,35] ; 2$ papers did not report original research $[8,13]$ and 5 did not present prevalence data for seclusion or restraint use $[8,19,28,26,33]$

Four of the 7 included studies had a pre-intervention/post-intervention design $(n=1,302)[6,17,18,21]$, two were descriptive studies $(n=590)[9,15]$, and the last one was a cross-sectional survey $(n=504)$ [32] (Table 1$)$.

Summary of the included studies

All 7 studies ( $n=2,393$; no $n$ available in one study [18]) reported on paediatric psychiatric inpatient samples, and all had prevalence data on SRU as the primary outcome measure. Studies were conducted in the US $(n=4)[9,17,18,21]$, Australia $(n=2)[6,15]$, and only one study was conducted in Europe [32]. One study $(n=442)$ reported on two consecutive time points, and 4 studies $(n=1,302)$ reported on SRU rates before and after a specific intervention. The studied interventions included a new model of care [18], a behavioural therapy oriented management programme [6], the introduction of a padded room as an alternative [17], and a collaborative problem solving approach for aggression [21]. Overall, the results across these studies were diverse, yet, SRU rates were substantial and generally decreased in response to a specific intervention.

Baseline SRU rates and global changes over time

Across in the studied populations, all studies found relatively high baseline rates of seclusion (weighed mean: $26 \%(n=1,296)$, range: $8.5 \%$ to $61 \%$ of patients; weighed mean: $67 / 1.000$ patient days ( $n=579$ ), range: 14.5 to $92 / 1.000$ patient days) and of restraints (weighed mean: $29 \%(n=1,083)$, range: $7.6 \%$ to $47 \%$ of patients; weighed mean: $42.7 / 1,000$ patient days 
( $n=579$ ), range: 21.2 to $56 / 1,000$ patient days) (Table 2). In four studies ( $n=1,302)$, an intervention, implemented to reduce seclusion and restraints, was generally successful.. After the intervention, there was a dramatic weighted mean reduction by $93.2 \%(82.8-97.0 \%)$ in the more restrictive use of restraints, accompanied by a reduction in duration of $54.2 \%$. There was only a small, weighted mean reduction in the use of less restrictive seclusions $(-0.6 \%)$ in those same studies. However, the results were heterogeneous $(-97.2 \%$ to $+71.0 \%)$, with the only increase in seclusions being reported in one study in which the intervention consisted of the introduction of the more frequently used padded seclusion room. In the other studies, seclusion episodes reduced by $74.7 \%$, accompanied by a decrease in duration of $32.4 \%$.

Description of specific results

Sourander et al. reported on four SRU techniques: seclusion, time-out, holding and physical restraints [32]. Time-out was defined as referral of the patient to her/his room to achieve behavioural control. Therapeutic holding was defined as physically restraining the patient by a team member to control aggressive behaviour; i.e., the therapist holds to patient while providing verbal reassurance and support. In a population of 294 boys and 191 girls, the authors found 40 periods of seclusion (8.5\%), 136 episodes of time-out (28.2\%), 125 episodes of holding (26.4\%) and 20 episodes of mechanical restraints $(4 \%)$. The authors indicate a preference for time-out and holding, but describe the overall frequency of SRU as high.

The paper by Donovan et al. reports an even higher prevalence of SRU [9]. In the first year of the study, there were 141 episodes of seclusion (61\%) and 109 episodes of mechanical restraints (47\%) in a population of 231 youngsters. The next year (not after a specific therapeutic intervention to reduce SRU, but following a federal institutional improvement programme) the respective frequencies were almost unchanged in a population of 211, i.e., $128(61 \%)$ episodes of seclusion and $106(50 \%)$ episodes of mechanical restraints. The authors, nevertheless, concluded that there were changes in SRU. This statement was based mainly on a significant reduction of the duration of restraint use (from 73.4 minutes to 62.3 minutes per episode) and on a $26 \%$ reduction of seclusion and restraint use combined as well as a $38 \%$ reduction in cumulative duration.

Gullick et al. only provided data on mechanical fixation during episodes of seclusion; in 92 of 97 (94\%) episodes mechanical fixation were used (94\%) [15] 
In 4 studies, authors evaluated the effect of specific interventions to reduce rates of SRU.

LeBel et al. studied the implementation of a new model of strength based care in an impatient unit [18]. In the period prior to the change, rates of SRU were 84.0 per 1,000 patient days in the child department, 72.2 per 1.000 patient days in the adolescent ward and 73.4 per 1,000 patient days in a mixed child and adolescent unit. After the introduction of the new model of care, there was a marked reduction of SRU by $59.8 \%$ down to: 22.8 SRU episodes per 1,000 patient days $(-72.9 \%)$ in the child department, 38.0 per 1,000 patient days $(-47.4 \%)$ in the adolescent group, and 30.1 per 1,000 patient days $(-59.0 \%)$ in the mixed ward [Leb]. A baseline $\mathrm{n}$ of patients studied was missing in this study. However, the reduction of SRU was demonstrated in more than $80 \%$ of the services assessed. The authors associated the reduction with the changed policies, but the time-frame post-intervention was relatively short (12 months), so the stability of the change remains uncertain.

Similarly, Dean et al. evaluated the effects of a behavioural therapy oriented management programme [6]. The authors distinguished different SRU techniques: seclusion, mechanical restraint and all interventions with a locked door. Seclusion was renamed locked time-out in the post-intervention period. The patient was placed in a designated room with an open door, which was only locked if the patient did not calm down. The relabeling and the rather vague concept of "all locked interventions" make the data for seclusions difficult to interpret. In the period prior to the intervention the mean frequency per month of the interventions was 10.7 for seclusion, 23.3 for mechanical restraint, and 10.7 for locked interventions. During the post intervention ( 6 months) there was a reduction of seclusions $(0.3$ episodes $=-97.2 \%)$ and mechanical restraint $(4.0$ episodes $=-82.8 \%)$, while there was an increase in all forms of locked interventions (13.8 episodes $=+35.5 \%$ ). According to the authors, this increase was mainly due to more episodes of locked time-out.

In a retrospective study Larson et al. evaluated the effects of the introduction of a padded seclusion room [17]. They evaluated 369 female adolescent patients aged between 13 and 17 years old. In a period of 18 months before the introduction of the new room 210 patients were admitted of whom $23(11 \%)$ required seclusion and $16(7.6 \%)$ required mechanical restraint. In the 18 months post intervention, there were 186 admissions with 27 $(14.5 \%=+31.8 \%)$ seclusions but only with $2(1.1 \%=-85.5 \%)$ mechanical restraint users. Both the number and duration of seclusion episodes increased from 14.5/1,000 patient days 
and 36.2 minutes per patient, to $24.8 / 1,000$ patient days $(+71.0 \% \%)$ and 64.3 minutes $(+77.6 \%)$, respectively. Although the increase was apparent, it did not reach statistical significance. The reduction in the more restrictive restraint use, however, was significant, from $21.2 / 1,000$ patient days to only $1.3 / 1,000$ patient day episodes (-93.9\%\%) post intervention.

The last, and only prospective, study by Martin et al. evaluated the impact of a collaborative problem solving approach for aggression [21]. The model provides alternative ways of coping and dealing with anger and frustrations and tries to prevent aggressive outbursts. The interventions were evaluated over a 5 year period, in which 998 patients were admitted and 2.230 restrictive interventions were recorded, 1,671 episodes of seclusion and 559 episodes of mechanical restraint use. Prior to the intervention, there were 432 seclusion episodes translating into an average of 36 seclusions per month, or a mean number of seclusions of $92 / 1,000$ patient days, with a mean duration of 27 minutes. After the implementation of the intervention, there was a significant reduction to 133 seclusions, on average 11 per month $(-69.4 \%)$ or $33 / 1,000$ patient days $(-64,1 \%)$, lasting 21 minutes ($22.2 \%$ ) on average. The reduction in the use of mechanical restraints was even greater (37.5 fold), decreasing from 263 restraints per year, with a monthly average of 22 restraints or 56 restraints per 1.000 patients days (lasting 41 minutes) to only 7 restraints in 2007 (-97.3\%), with a mean of 0.6 restraints per month $(-68.2 \%)$ or 1.7 restraints per 1,000 patient days ($97.0 \%)$, lasting only 18 minutes (-56.1\%). All SRU combined decreased 5 fold with the intervention.

\section{Correlates and Risk Factors}

Some studies also evaluated a limited number of risk-factors and potential predictors. The most consistent findings were aggression and/or violent behaviour, both past and current, suicidal behaviour, more severe psychopathology $[6,15,21,32]$ and non-White ethnicity in some US studies [9,21]. In the study by Donovan et al., both emergency admissions and younger age were associated with higher SRU rates, this finding contrasts with those by Martin et al. who found higher restraint use in older patients $[9,21]$. One study found out-ofhome placement to be a risk-factor [32], while another study identified poorer family functioning [15].

Quality assessment 
The included papers were scored on a seven point scale [12], and results are presented in Table 3. A "+" indicates whether the criterion is fulfilled, a "+/-" indicates doubt or uncertainty, and a "-" means that the paper failed on this item.

Only the paper by Sourander et al. met all quality criteria [32]. In all other studies, a clear sampling method was missing. For the study by Martin et al., this was the only missing item [21]. Larson et al. and Gullick et al. also failed to report missing data [15,17]. Donovan et al. and Dean et al. did not provide a clear definition of SRU [6,9]. The last paper mentions missing data, but failed to the report the sample size [9]. Like all other publications, the paper of LeBel et al., formulated a clear research question and reported results, but it did not meet any of the other criteria, and did not mention the total $n$ of the sample [18]. The authors did not report missing data, a description of the assessment instruments or a clear definition of SRU. As such, the data-analysis was adequate, but the paper failed to report essential data. 


\section{Discussion and conclusion}

The limited literature on SRU in youngsters indicates that these procedures are frequently used. Four studies were from the US [9,17,18,21] and 2 from Australia [6,15], while only 1 study was performed in Europe [32]. Data on SRU in most European countries are lacking. Only 3 of the 4 studies had a clear definition of seclusion and restraint procedures. This limits an overall comparison and analysis of the presented data.

Primary outcomes were prevalence rates, reported either as the proportion of patients restrained/secluded or as the number of restraints/seclusions per number of patient days. The rates that were found in the indentified studies of the past ten years lead all authors to conclude that SRU rates were high. Although the prevalence rates of SRU differed between studies, the weighted mean average rates indicated that more than one out of four patients had at least one seclusion episode and $29 \%$ of patients had at least one restraint episode. Overall, the baseline rates did not differ much from the results in the publications from before the year 2000, but all studies that reported on a policy change or intervention showed that $\mathrm{SRU}$, measured in different ways, could be significantly reduced. This reduction post intervention was particularly pronounced for the most restrictive and potentially dangerous use of restraints. Although one study, in which the intervention consisted of the introduction of a special seclusion room, showed a compensatory increase in seclusions while restraints decreased dramatically, in the remaining studies, both restraints and seclusions decreased.

On the other hand, the literature on risk-factors and potential predictors of SRU remains sparse, limiting pre-emptive efforts aimed at preventing the use of seclusion and, especially, restraints.

The high rates of SRU in this specific population is of concern. SRU are an infringement on the patients' rights and other research has indicated that SRU can lead to severe consequences, both psychological and physical $[5,22,26,27,29]$. Authors argue that in specific situations and for specific indications SRU cannot be avoided, but advocate for the implementation of strict guidelines about its use, the possible indications and close monitoring during SRU. Most of these authors agree that in daily clinical practice, such guidelines are not in place $[9,18,32]$.

A strength of this review is that the systematic search identified the most recent studies on SRU in youngsters. Previous publications and reviews did not specifically focus on 
prevalence rates or the effects of interventions designed to reduce SRU. A limitation of our study was that only a small number of studies, with relatively small n's, could be included and that a generalisation of the results is problematic due to different methodologies and definitions of SRU.

There is an urgent need for more research on SRU in children and adolescents. Future studies should utilize clearer definitions and focus on prevalence rates, predictors, clinical outcomes and effectiveness indicators of the interventions. The practice parameters of the American Academy of Child and Adolescent Psychiatry provide these definitions and also contain guidelines on procedures and monitoring [22]. Recently, six core elements have been proposed to reduce SRU both in adults as well as youngsters: leadership support of organisational change; use of data to inform practice; workforce development; use of seclusion and restraint prevention tools; inclusion of patients and families; and rigorous debriefing after restrictive events [16]. Sourander et al. suggest that these guidelines should also be implemented in Europe, leading both to better treatment standards and data that can be compared across different sites [32]. There is a clear need for consensus building and guideline development for the most appropriate use of seclusions and restraint in mentally ill youth, taking into account various relevant factors related to the patient, presentation, setting, alternatives, etc. Such guidelines are sorely needed in the EU as, so far, little research has been done to guide clinicians. 


\section{Acknowledgements}

None

\section{Funding}

None

\section{Authors contribution}

$\mathrm{MDH}$ wrote the first draft of the paper. ND did the literature search and data extraction. All authors contributed to the subsequent versions of the text. 


\section{References}

1. Angold A, Pickles A (1993) Seclusion on an adolescent unit. J Child Psychol Psychiatry 34(6):975-989.

2. Bell $L$ (1997) The physical restraint of young people. Child Family Soc Work 1:37-47.

3. Busch AB, Shore MF (2000) Seclusion and restraint: A review of recent literature. Harv Rev Psychiatry 8(5):261-270.

4. Day DM (2002) Examining the therapeutic utility of restraints and seclusion with children and youth: the role of theory and research in practice. Am J Orthopsychiatry 72(2):266-278.

5. De Hert M, Einfinger G, Scherpenberg E, Wampers M, Peuskens J (2010) The prevention of deep venous thrombosis in physically restrained patients with schizophrenia. Int J Clin Pract 64(8):1109-1115.

6. Dean AJ, Duke SG, George M, Scott J (2007) Behavioral management leads to reduction in aggression in a child and adolescent psychiatric inpatient unit. J Am Acad Child Adolesc Psychiatry 46(6):711-720.

7. Delaney KR (2006) Evidence base for practice: reduction of restraint and seclusion use during child and adolescent psychiatric inpatient treatment. Worlviews Evid Based Nurs 3(1):19-30.

8. Delaney KR, Fogg L (2005) Patient characteristics and setting variables related to use of restraint on four inpatient psychiatric units for youths. Psychiatr Serv 56(2):186-192.

9. Donovan A, Plant R, Peller A, Siegel L, Martin A. (2003) Two-year trends in the use of seclusion and restraint among psychiatrically hospitalized youths. Psychiatr Serv 54(7):987-993.

10. Earle KA, Forquer SL (1995) Use of seclusion with children and adolescents in public psychiatric hospitals. Am J Orthopsychiatry 65(2):238-244.

11. Fassler D, Cotton N (1992) A national survey on the use of seclusion in the psychiatric treatment of children. Hosp Community Psychiatry 43:370-374.

12. Forbes A, Griffiths $P$ (2002) Methodological strategies for the identification and synthesis of 'evidence' to support decision-making in relation to complex healthcare systems and practices. Nurs Inq 9:141-155.

13. Fryer MA, Beech M, Byrne GJA (2004) Seclusion use with children and adolescents: an Australian experience. Aust N Z J Psychiatry 38.:26-33. 
14. Grigg M (2006) Eliminating seclusion and restraint in Australia. Int J Ment Health Nurs 15(4):224-5.

15. Gullick K, McDermott B, Stone P, Gibbon P (2005) Seclusion of children and adolescents: psychopathological and family factors. Int J Ment Health 14:37-43.

16. Huckshorn KA (2005) Six core strategies to reduce the use of seclusion and restraint Planning tool. National Association of State Mental Health Program Directors. Aivalable at: http://www.wafca.org/, accessed 01102010.

17. Larson TC, Sheitman BB, Kraus JE, Mayo J, Leidy L (2008) Managing treatment resistant violent adolescents: a step forward by substituting seclusion for mechanical restraint?. Adm Policy Ment Health 35:198-203.

18. LeBel J, Stromberg N, Duckworth K, Kerzner J, Goldstein R, Weeks M, Harper G, LaFlair L, Sudders M (2004) Child and adolescent inpatient restraint reduction: a state initiative to promote strength-based care. J Am Acad Child Adolesc Psychiatry 43(1):37-45.

19. Leidy, B.D., Haugaard, J.J., Nunno, M.A., Kwartner, J.K. (2006) Review of restraint data in a residential treatment center for adolescent females. Child Youth Care Forum 35:339-352.

20. Luiselli JK, Bastien JS, Putnam RF (1998) Behavioral assessment and analysis of mechanical restraint utilization on a psychiatric child and adolescent inpatient setting. Behavioral Interventions 13:147-155.

21. Martin A, Krieg H, Esposito F, Stubbe D, Cardona L (2008) Reduction of restraint and seclusion through collaborative problem solving: a five-year prospective inpatient study. Psychiatr Serv 59(12):1406-1412.

22. Masters KJ, Bellonci C, Bernet W, Arnold V, Beitchman J, Benson RS, Bukstein O, Kinlan J, McClellan J, Rue D, Shaw JA, Stock S (2002) Practice parameter for the prevention and management of aggressive behavior in child and adolescent psychiatric institutions, with special reference to seclusion and restraint. J Am Acad Child Adolesc Psychiatry 41(2 suppl):4S-25S.

23. Millstein KH, Cotton NS (1990) Predictors of the use of seclusion on an inpatient child psychiatric unit. J Am Acad Child Adolesc Psychiatry 29(2):256-264.

24. Mohr WK, Mahon MM, Noone MJ (1998) A restraint on restraints: the need to reconsider the use of restrictive interventions. Arch Psychiatr Nurs 12(2):95-106. 
25. Nelstrop L, Chandler-Oatts J, Bingley W, Bleetman T, Corr F, Cronin-Davis J, Fraher DM, Hardy P, Jones S, Gournay K, Johnston S, Pereira S, Pratt P, Tucker R, Tsuchiya AA (2006) Systematic review of the safety and effectiveness of restraint and seclusion as interventions for the short-term management of violence in adult psychiatric inpatient settings and emergency departments. Worldviews Evid Based Nurs 3(1):8-18.

26. Nunno MA, Holden MJ, Tollar A (2006) Learning from tragedy: a survey of child and adolescent restraint fatalities. Child Abuse Negl 30:1333-1342.

27. Oberleitner LL (2000) Aversiveness of traditional psychiatric patient restriction. Arch Psychiatr Nurs 14(2):93-97.

28. Petti TA, Mohr WK, Somers JW, Sims L (2001) Perceptions of seclusion and restraint by patients and staff in an intermediate-term care facility. J Child Adolesc Psychiatr Nurs 14(3):115-127.

29. Prinsen EJ, Van Delden JJ (2009) Can we justify eliminating coercive measures In psychiatry? J Med Ethics 35(1):69-73.

30. Salias E, Fenton M (2000) Seclusion and restraint for people with serious mental Illnesses. The Cochrane Database of Systemat Rev (2):CD 001163.

31. Singh NN, Singh SD, Davis CM, Latham LL, Ayers JG (1999) Reconsidering the use of seclusion and restraints in inpatient child and adult psychiatry. J Child Fam Stud 8(3):243-253.

32. Sourander A, Ellilä H, Välimäki M, Piha J (2002) Use of holding, restraints, seclusion and time-out in child and adolescent psychiatric in-patient treatment. Eur Child Adolesc Psychiatry 11:162-167.

33. Steckley L, Kendrick A (2008) Physical restraint in residential childcare: the experiences of young people and residential workers. Childhood 15(4):552-569.

34. Steinert $T$, Lepping $P$, Bernhardsgrütter $R$, Conca $A$, Hatling $T$, Janssen $W$, KeskiValkama A, Mayoral F, Whittington R (2010) Incidence of seclusion and restraint in psychiatric hospitals: a literature review and survey of international trends. Soc Psychiatry Psychiatr Epidemiol 45(9):889-897.

35. Troutman B, Myers K, Borchardt C, Kowalski R, Bubrick J (1998) Case study: when restraints are the least restrictive alternative for managing aggression. $J$ Am Acad Child Adolesc Psychiatry 37(5):554-558.

able 1: Overview of the included publications 


\begin{tabular}{|c|c|c|c|c|}
\hline Design & Aim/research question & Population & Outcome measures & Results \\
\hline $\begin{array}{l}\text { ss-sectional } \\
\text { rey-design }\end{array}$ & $\begin{array}{l}\text { Evaluation of seclusion and } \\
\text { restraints use in child and } \\
\text { adolescent wards in Finland }\end{array}$ & $\begin{array}{l}\text { Admitted children and } \\
\text { adolescents } \\
N=504 \\
\text { Mean age: } \\
\widehat{D}=11.4 \text { years } \\
\phi=13.9 \text { years }\end{array}$ & $\begin{array}{l}\text { Prevalence of seclusion and } \\
\text { restraints use }\end{array}$ & $\begin{array}{ll}\text { Prevalence in N episodes: } \\
\text { - } \quad \text { Seclusion: } 43(8.5 \%) \\
\text { - } \quad \text { Time-out: } 142(28.2 \%) \\
\text { - } \quad \text { Holding: } 133(26.4 \%) \\
\text { - } \quad \text { Mechanical restraints: } 20(4 \%\end{array}$ \\
\hline criptive study & $\begin{array}{l}\text { Evaluation of seclusion and } \\
\text { restraints use in child and } \\
\text { adolescent ward over a } 2 \text { year } \\
\text { period, US }\end{array}$ & $\begin{array}{l}\text { Admitted children and } \\
\text { adolescents } \\
\mathrm{N}=442\end{array}$ & $\begin{array}{l}\text { Prevalence of seclusion and } \\
\text { restraints use }\end{array}$ & $\begin{array}{ll}\text { Prevalence: } \\
\text { - } & \text { Year } 1(2000, \mathrm{n}=231): \\
\text { - } & \text { Seclusion: } 141(61 \%) \\
\text { - } & \text { Mechanical restraints : } 109 \\
\text { - } & \text { Year } 2(2001, \mathrm{n}=211): \\
\text { - } & \text { Seclusion: } 128(61 \%) \\
\text { - } & \text { Mechanical restraints : } 106(! \\
\text { - } & \text { Total population }(\mathrm{n}=422): \\
\text { - } & \text { Seclusion: } 269(61 \%) \\
\text { - } & \text { Mechanical restraints : } 215\end{array}$ \\
\hline $\begin{array}{l}\text { - intervention - } \\
\text { t- intervention } \\
\text { ign }\end{array}$ & $\begin{array}{l}\text { Evaluation of the effects on } \\
\text { restraint use after the } \\
\text { introduction of a model of } \\
\text { strength-based care, US }\end{array}$ & $\begin{array}{l}\text { Admitted children and } \\
\text { adolescents in one US } \\
\text { state } \\
\mathrm{N} \text { not mentioned } \\
\text { - } \quad \text { Acute psychiatric } \\
\quad \text { wards in } 60 \\
\quad \text { hospitals } \\
\text { - } 10 \text { psychiatric } \\
\text { inpatient facilities }\end{array}$ & $\begin{array}{l}\text { Prevalence of seclusion and } \\
\text { restraints use before and after an } \\
\text { intervention: } \\
\text { - } \quad \mathrm{N} \text { episode per } 1,000 \text { patient } \\
\text { days } \\
\text { - Duration per episode in hours }\end{array}$ & $\begin{array}{ll}\text { Prevalence in episodes per } 1,000 \\
\text { - } & \text { Pre-intervention period (111 } \\
\text { 2000): } \\
\text { - } \quad \text { Child unit: } 84 \\
\text { - } \quad \text { Adolescent unit: } 72.2 \\
\text { - } \quad \text { Mixed unit: } 73.4 \\
\text { - } \quad \text { Post-intervention period (10 } \\
\text { 2002): } \\
\text { - } \quad \text { Child unit: } 22.8(-72.9 \%) \\
\text { - } \quad \text { Adolescent unit: } 38(-47.4 \%) \\
\text { - } \quad \text { Mixed unit: } 30.1(-59.0 \%)\end{array}$ \\
\hline $\begin{array}{l}\text { criptive, } \\
\text { lorative design }\end{array}$ & $\begin{array}{l}\text { Evaluation of seclusion and } \\
\text { restraints use on a ward in } \\
\text { Australia with focus on: } \\
\text { - } \quad \text { Antecedent events } \\
\text { - } \quad \text { Management strategies } \\
\text { - } \quad \text { Risk-factors }\end{array}$ & $\begin{array}{l}\text { Admitted children and } \\
\text { adolescents in a } \\
\text { psychiatric ward in } \\
\text { Australia } \\
\mathrm{N} \text { not clear (148?) }\end{array}$ & $\begin{array}{l}\text { Prevalence of seclusion and } \\
\text { restraints use, focus on: } \\
\text { - } \quad \text { Psychopathology } \\
\text { - } \quad \text { Mental health parents } \\
\text { - } \quad \text { Functioning familial environment } \\
\text { - } \quad \text { Recent life-events }\end{array}$ & 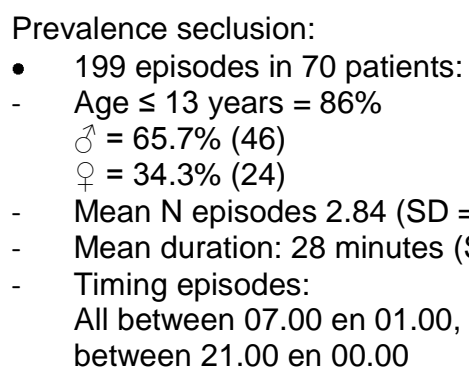 \\
\hline & & & & $\begin{array}{l}\text { Prevalence mechanical restraints } \\
\text { episodes): } 94.8 \%(92)\end{array}$ \\
\hline $\begin{array}{l}\text {-intervention - } \\
\text { t-intervention } \\
\text { ign }\end{array}$ & $\begin{array}{l}\text { Evaluation of the introduction of } \\
\text { a behaviour management } \\
\text { programme on a ward, US }\end{array}$ & $\begin{array}{l}\text { Admitted children and } \\
\text { adolescents in a } \\
\text { psychiatric ward in } \\
\text { Australia } \\
\mathrm{N}=151 \text {, mean age } 13 \\
\text { years }\end{array}$ & $\begin{array}{l}\text { Prevalence aggressive behaviour, } \\
\text { outcome measures on ward level: } \\
\text { - Injuries } \\
\text { - } \quad \text { Involvement security staff } \\
\text { - } \quad \text { Mechanical restraints } \\
\text { - } \quad \text { Seclusion } \\
\text { - } \quad \text { Locked time-out } \\
\text { - } \quad \text { HoNOSCA }\end{array}$ & $\begin{array}{ll}\text { Prevalence in mean } N \text { episodes } \\
\text { - } & \text { Pre intervention period ( } n=65 \\
- & \text { Aggression incidents: } 84.0 \\
- & \text { Mechanical restraints : } 23.3 \\
\text { - } & \text { Seclusion: } 10.7 \\
- & \text { All episodes of locked interve } \\
\text { - } & \text { Duration of locked interventi } \\
- & \text { Post intervention period }(n=8 \\
- & \text { Aggression incidents: } 18.5 \\
- & \text { Sechanical restraints : } 4.0 \\
- & \text { Episodes of locked interventi } \\
- & \text { Duration of locked interventi } \\
& 16.8(-54.0 \%)\end{array}$ \\
\hline
\end{tabular}


- intervention t- intervention ign
Evaluation of the introduction of a padded room on mechanical restraint use
Admitted female adolescents (13 to 17 years old) in an acute ward

$\mathrm{N}=396$
Prevalence of seclusion and restraints use before and after an intervention:

- $\quad \mathrm{N}$ secluded patients

- Mean $\mathrm{N}$ episode per month and per 1,000 patient days

- Mean duration per patient in minutes per month spective prervention - postrvention design
Evaluation of the introduction of a collaborative problem solving programme on a ward on seclusion and restraint use
Admitted children and adolescents $\mathrm{n}=755$ (998 admissions) Mean age 11 years
Prevalence of seclusion and restraints use before and after an intervention:

- $\quad \mathrm{N}$ episodes per year/month/1,000 patient days

- Mean duration in minutes per episode
Prevalence seclusion:

- Pre intervention period:

- $\quad$ N admitted patients: 210

- $\quad$ N secluded patients: 23 (11\%

- $\quad$ Mean N episodes per 1,000 ( \pm SD 13.0)

- $\quad$ Mean duration in minutes pe patient : 36.2 ( \pm SD 37.0)

- Post- intervention period:

- $\quad$ N admitted patients : 186

- $\quad$ N secluded patients : 27 (14.

- $\quad$ Mean N episodes per 1,000 ( \pm SD 23.8) (+71.0\%)

- $\quad$ Mean duration in minutes pe patient: 64.3 ( \pm SD 64.4) (+7

Prevalence mechanical restraint

- Pre intervention period:

- $\quad$ N admitted patients: 210

- $\quad \quad \quad N$ restrained patients: 16 (7.6

- $\quad$ Mean N episodes per 1,000 ( \pm SD 34.3)

- Post intervention period:

- $\quad$ N admitted patients : 186

- $\quad \mathrm{N}$ restrained patients: $2\left(1,1^{\circ}\right.$

- $\quad$ Mean N episodes per 1,000 SD 4.1) (-93.9\%)

Prevalence seclusion:

Total over period of 5 years: 167

- $\quad$ Pre intervention period (2003

- N episodes:

- Per year: 432

- Per month: 36 ( \pm SD 15)

- Per 1,000 patient days:

- $\quad$ Mean duration in minutes: 27

- $\quad$ Post intervention period (200

- N episodes:

- Per year: 133 (-69.2\%)

- Per month: 11 ( \pm SD 7)

- Per 1,000 patient days:

- $\quad$ Mean duration in minutes: 2

Prevalence mechanical restraint Total over period of 5 years: 559

- $\quad$ Pre intervention period (2003

- N episodes

- Per year: 263

- Per month: 22 ( \pm SD 13)

- Per 1,000 patient days:

- $\quad$ Mean duration in minutes: 4

- $\quad$ Post intervention period (200

- N episodes:

- Per year: 7 (-97.3\%)

- Per month: 0.6 ( \pm SD 0.

- Per 1,000 patient days: Mean duration in minutes: 18 
Table 2: Baseline rates of seclusion and restraint use and global changes over time after intervention

\begin{tabular}{|c|c|c|c|c|c|}
\hline dy & $\mathbf{N}$ & Seclusion & Restraint & $\begin{array}{c}\text { Effect of intervention: } \\
\text { Seclusion } \\
\text { Episodes / } 1000 \text { patient days } \\
\text { [Duration] }\end{array}$ & $\begin{array}{c}\text { Effect of interven } \\
\text { Restraint } \\
\text { Episodes / } 1000 \text { patic } \\
\text { [Duration] }\end{array}$ \\
\hline l., 2002 & 504 & $40(8.5 \%)$ & $153(30.4 \%)$ & na & na \\
\hline , 2003 & 231 & $\begin{array}{c}141(61 \%) \\
76.5 / 1,000 \text { PD }\end{array}$ & $\begin{array}{c}109(47 \%) \\
54 / 1,000 \text { PD }\end{array}$ & na & na \\
\hline 04 & na & $\begin{array}{l}\text { All units combined } \\
\text { SRU 76/1,000 PD }\end{array}$ & na & $\begin{array}{c}-59.8 \% \\
\text { (all SRU, all units) }\end{array}$ & $\begin{array}{c}-59.8 \% \\
\text { (all SRU, all unit }\end{array}$ \\
\hline 005 & $148(?)$ & $70(43.7 \%)$ & na & na & na \\
\hline 07 & 65 & $8(12.3 \%)$ & na & $\begin{array}{c}-97.2 \% \\
\text { (Seclusion) } \\
+35.5 \% \\
\text { (“locked intervention") } \\
\text { [duration: }-54.0 \%]\end{array}$ & $-82.8 \%$ \\
\hline 2008 & 210 & $\begin{array}{c}23(11 \%) \\
14.5 / 1,000 \mathrm{PD}\end{array}$ & $\begin{array}{c}16(7.6 \%) \\
21.2 / 1,000 \mathrm{PD}\end{array}$ & $\begin{array}{c}+71.0 \% \\
\text { ("padded room" seclusion) } \\
\text { (duration: }+77.6 \%)\end{array}$ & $\begin{array}{c}-93.9 \% \\
\text { (restraint use) }\end{array}$ \\
\hline 008 & 138 & $\begin{array}{c}52(38 \%) \\
92 / 1,000 \mathrm{PD}\end{array}$ & $\begin{array}{c}42(30 \%) \\
56 / 1,000 \text { PD }\end{array}$ & $\begin{array}{c}-64.1 \% \\
\text { [duration: }-22.2 \% \text { ] }\end{array}$ & $\begin{array}{c}-97.0 \% \\
\text { [duration: }-56.0 \%\end{array}$ \\
\hline an & & $26 \%(n=1,296)$ & $29.4 \%(n=1,083)$ & & \\
\hline an & & $67 / 1,000$ PD $(n=579)$ & 42.6/1,000 PD $(n=579)$ & $\begin{array}{c}-0.6 \% \\
\text { (seclusion, incl. padded room) } \\
\text { [duration: }+23.5 \% \text { ] } \\
-74.7 \% \\
\text { (other seclusion) } \\
\text { [duration: }-32.4 \% \text { ] }\end{array}$ & $\begin{array}{c}-93.2 \% \\
\text { [duration: }-56.0 \%\end{array}$ \\
\hline
\end{tabular}

(na: not available; SRU: seclusion and restraint use; PD patient days) 
Table 1: Quality assessment of the studies.

\begin{tabular}{|c|c|c|c|c|c|c|}
\hline Criterion & $\begin{array}{c}\text { Clear aim and/or } \\
\text { research } \\
\text { question }\end{array}$ & $\begin{array}{l}\text { Description of } \\
\text { sampling } \\
\text { method }\end{array}$ & $\begin{array}{l}\text { Description of } \\
\text { non-responders } \\
\text { and/or missing } \\
\text { data }\end{array}$ & $\begin{array}{l}\text { Clear } \\
\text { description } \\
\text { of seclusion } \\
\text { and } \\
\text { restraints } \\
\text { use }\end{array}$ & $\begin{array}{l}\text { Description of } \\
\text { the assessment } \\
\text { method and/or } \\
\text { instruments }\end{array}$ & $\begin{array}{l}\text { Correct } \\
\text { analysis }\end{array}$ \\
\hline Sourander et al., 2002 & + & + & + & + & + & + \\
\hline Donovan et al., 2003 & + & - & + & - & + & + \\
\hline LeBel et al., 2004 & + & - & - & - & - & $+/-$ \\
\hline Gullick et al., 2005 & + & - & - & + & + & + \\
\hline Dean et al., 2007 & + & - & $+/-$ & - & + & + \\
\hline Larson et al., 2008 & + & - & - & + & + & + \\
\hline Martin et al., 2008 & + & - & + & + & + & + \\
\hline
\end{tabular}

(+: present; +/-: unclear or doubtful; -: absent)

36. 